\title{
PARTISIPASI NELAYAN DALAM PENGELOLAAN KAWASAN KONSERVASI LAUT KABUPATEN CIAMIS
}

\author{
Oleh \\ Sopiyan Danapraja \\ Dosen Jurusan Penyuluhan Perikanan Sekolah Tinggi Perikanan
}

\begin{abstract}
ABSTRAK
Peningkatan kesadaran dan keterlibatan masyarakat dalam pengelolaan Kawasan Konservasi Laut Kabupaten Kabupaten Ciamis ditujukan untuk meyakinkan masyarakat akan manfaat perlindungan kawasan tersebut. Karenanya peran serta masyarakat harus dilibatkan pada perencanaan, pelaksanaan, pemecahan kendala dan berbagai kemungkinan manfaat yang dapat diperoleh dari pengelolaan kawasan konservasi. Tujuan penelitian mengkaji hubungan karakteristik dengan persepsi dan partisipasi masyarakat, persepsi dan partisipasi dalam pengelolaan Kawasan Konservasi Laut (KKL) Kabupaten Ciamis. Metode penelitian adalah survei melalui analisis korelasi dan multivariat.

Karakteristik responden sebagai berikut, umumnya berusia 35 - 44 tahun (44\%), berpendidikan tinggi (52\%), pernah mengikuti pendidikan non formal (97\%), mempunyai tanggungan 2 anak (44\%), pengalaman lebih dari 10 tahun (76\%), pernah membeli alat ke luar daerah (94\%) dan pernah mencari informasi ke luar daerah (84\%). Tingkat partisipasi dalam pengelolaan KKL 32\% sering mengikuti (baik). Responden diketahui 25,7\% sering mengikuti kegiatan perencanaan, 25,8\% sering mengikuti kegiatan penyuluhan/ pembinaan dan 16\% sering ikut dalam pemecahan masalah pengelolaan KKL.

Hasil analisis menunjukan karakteristik mempengaruhi tingkat partisipasi responden. Terdapat korelasi yang erat antara persepsi dan partisiapsi responden dalam pengelolaan KKL (koefisien korelasi 0,563 dan p-value 0,00).
\end{abstract}

Kata kunci : nelayan, karakteristik, partisipasi, pengelolaan, Kawasan Konservasi Laut.

\section{PENDAHULUAN}

\section{Latar Belakang}

Pemerintah Kabupaten Ciamis telah menerbitkan Peraturan Bupati Ciamis Nomor 15 Tahun 2008 tentang Pencadangan Lokasi Kawasan Konservasi Laut (KKL) Kabupaten Ciamis, sebagai langkah nyata keseriusan (komitmen) mengelola sumberdaya kelautan dan perikanan. Penerbitan peraturan tersebut merupakan implementasi dari Undang-Undang No. 27 Tahun 2007 dan Undang-Undang No. 32 Tahun 2004.

Salah satu faktor kunci membangun pengelolaan kawasan konservasi adalah keterlibatan atau partisipasi masyarakat. Menurut Margono (1985) dalam Susiatik (1998), bahwa partisipasi masyarakat dalam pembangunan sangat mutlak diperlukan untuk keberhasilan pembangunan, pada umumnya dapat dikatakan bahwa tanpa partisipasi 
masyarakat setiap proyek pembangunan harus dinilai tidak berhasil. Bahkan secara tegas Gawel (1984) dalam White dkk. (1994) menyatakan bahwa tidak ada pengelolaan sumberdaya alam yang berhasil tanpa melibatkan masyarakat lokal sebagai pengguna dari sumberdaya alam.

Partisipasi masyarakat ini dapat diterjemahkan sebagai kontribusi masyarkat dalam fungsi-fungsi perencanaan, pengelolaan, pengambilan keputusan, monitoring dan evaluasi. Sehingga peran ini dapat dilihat sebagai kompromi kewenangan dalam skema community based management (Pomeroy dan Berkes, 1997).

\section{Perumusan Masalah}

Dalam peraturan Pencadangan Kawasan Konservasi Laut Kabupaten Ciamis, disebutkan didasarkan pada asas manfaat, keterpaduan, keseimbangan, berkelanjutan, berkeadilan, dan berbasis masyarakat. Asas terakhir dapat dijabarkan sebagai partisipasi nelayan sebagai salah satu stakeholder. Partisipasi nelayan dalam pengelolaan berkaitan erat dengan pengaruh yang dimiliki dan keterkaitan nelayan dengan KKL Kabupaten Ciamis. Kedua hal tersebut sangat tergantung pada perspektif dan kapasitasnya mempengaruhi keputusan pengelolaan. Semakin tinggi kapasitasnya, akan semakin tinggi pengaruhnya. Namun pengaruh tersebut sangat ditentukan oleh perspektif stakeholder. Dalam praktek, implementasi partisipasi masyarakat ditentukan juga oleh peluang yang diberikan pemerintah kepada masyarakat.

\section{Tujuan}

Tujuan penelitian ini adalah mengetahui partisipaasi nelayan dalam pengelolaan kawasan konservasi. Secara khusus penelitian ini bertujuan untuk mengkaji :
1. Karakteristik (kapasitas) masyarakat nelayan Kawasan Konservasi Laut Kabupaten Ciamis.

2. Tingkat partisipasi masyarakat nelayan dalam mengelola Kawasan Konservasi Laut Kabupaten Ciamis.

3. Keeratan hubungan karakteristik (kapasitas) masyarakat nelayan dengan partisipasi mereka mengenai mengelola Kawasan konservasi Laut Kabupaten Ciamis.

\section{METODE PENELITIAN}

\section{Waktu dan Lokasi Penelitian}

Penelitian dilakukan pada bulan 3 Mei - 14 Juli 2012 di Kawasan Konservasi Laut Kabupaten Ciamis Provinsi Jawa Barat. Total luas kawasan KKLD mencakup 29.823,986 ha, yang terdiri atas zona inti seluas 708,577 ha, zona pemanfaatan I seluas $2.331,577$ ha, zona pemanfaatan II seluas 1.947,204 ha, zona pemanfaatan III seluas $1.365,538$ ha, dan zona perikanan berkelanjutan seluas $23.471,525$ ha.

\section{Jenis dan Sumber Data}

Jenis data yang akan dikumpulkan dari para responden adalah karakteristik responden, persepsi mereka terhadap pengelolaan kawasan konservasi, partisipasi mereka dalam pengelolaan kawasan konservasi dan peran pemerintah yang berkaitan dengan partisipasi mereka. Berikut adalah rincian dari jenis-jenis data tersebut.

a. Karakteristik responden mencakup umur, pendidikan, kondisi sosial ekonomi rumah tangga, pengalaman kerja dan tingkat keterbukaan.

b. Partisipasi masyarakat dalam proses pengelolaan KKL tersebut dalam bentuk kegiatan atau keterlibatan fisik maupun non-fisik. 
Rincian dari jenis-jenis data yang akan dikumpulkan ini tertera dalam kuisoner yang dijadikan pegangan dalam melakukan wawancara terhadap responden. Selain data primer yang dikumpulkan langsung dari para responden, penelitian ini juga mengumpulkan data sekunder yang berkaitan dengan keadaan umum kondisi geografis, demografis lokasi penelitian. Data yang diperoleh dikumpulkan dengan beberapa teknik yaitu teknik observasi (pengamatan), teknik interview (wawancara) dan kuesioner.

\subsection{Populasi dan Sampel}

Populasi dalam penelitian adalah Rumah Tangga Perikanan (RTP) nelayan yang melakukan operasi penangkapan di KKL Kabupaten Ciamis. Rumah Tangga Perikanan (RTP) yang melakukan operasi penangkapan di Kawasan Konservasi Laut Daerah Kabupaten Ciamis berjumlah 1.658 orang (BPS Ciamis, 2011), yang menyebar pada enam alat tangkap yang digunakan yaitu dogol, jaring insang (gillnet), jaring tiga lapis (tramell net), bagan, arad dan rawai.

Menurut Koentjaraningrat (1997) bagian-bagian dari keseluruhan (populasi) yang menjadi obyek sesungguhnya dari suatu penelitian itulah yang disebut sampel, dan metodologi untuk menyeleksi individuindividu masuk kedalam sampel yang refresentatif itulah yang disebut sampling. Sampel (responden) ditentukan dengan teknik purposive sampling, dimana pengambilan sampel dihentikan bila jumlahnya telah memenuhi dan sampel yang diperoleh diasumsikan random.

Pengambilan sampel menggunakan teknik sampling kebetulan (accidental sampling) adalah mengambil responden sebagai sampel berdasarkan kebetulan, yaitu siapa saja yang secara kebetulan bertemu dengan peneliti dapat digunakan sebagai sampel bila orang yang kebetulan ditemui cocok sebagai sumber data (Sugiyono 2006). Keuntungan dari pada teknik ini adalah terletak pada ketepatan peneliti memilih sumber data sesuai dengan variabel yang diteliti (Arikunto, 2002).

Perhitungan besarnya responden (sampel) dengan menggunakan rumus Solvin (Umar, 2004), dengan tingkat kesalahan 10\%. Berdasarkan jumlah populasi dan rumus Slovin serta pertimbangan lain, maka jumlah sampel penelitian ini sebanyak 100 responden (Tabel 1).

Tabel 1. Jumlah Responden/sampel.

\begin{tabular}{|l|l|c|c|}
\hline No. & Kecamatan & RTP & $\begin{array}{c}\text { Jumlah sampel/ } \\
\text { Responden (orang) }\end{array}$ \\
\hline 1 & Dogol & 228 & 20 \\
\hline 2 & Gillnet & 638 & 25 \\
\hline 3 & Tramel net & 303 & 20 \\
\hline 4 & Bagan & 29 & 5 \\
\hline 5 & Rawai & 469 & 25 \\
\hline 6 & Arad & 27 & 5 \\
\hline Jumlah & & $\mathbf{1 . 6 5 8}$ & $\mathbf{1 0 0}$ \\
\hline
\end{tabular}

\section{Analisa Data}

Analisa data penelitian guna menjawab masalah yang telah diajukan (dirumuskan), digunakan teknik analisis sebagai berikut : a. Data karakteristik, partisipasi masingmasing dianalisis secara univariat (jumlah, mean (rata-rata), persentase).

b. Untuk mengungkapkan gambaran, komposisi data dan hubungan antar variabel serta memberi "isyarat" adanya hubungan kausalitas antar 
variabel menggunakan tabulasi silang (cross tabulasi) dan untuk mengetahui hubungan kausalitas dua variabel digunakan uji chi-square Tabel Kontingensi (Subiyakto, 1994).

$$
f_{e_{i j}}=\frac{\left(\sum f_{0_{i}}\right)\left(\sum f_{0_{j}}\right)}{n}
$$

dengan derajat kebebasan :

$$
\text { d. } f .=(r-1)(k-1)
$$

$\chi^{2}$ diperoleh dengan rumus :

$$
\chi^{2}=\sum \frac{\left(f_{0}-f_{e}\right)^{2}}{f_{e}}
$$

\section{HASIL DAN PEMBAHASAN}

\section{Hasil}

Karakteristik responden dalam penelitian ini secara umum berusia 35 44 tahun (44\%) dan sebagian besar $(88 \%)$ berusia produktif, berpendidikan tinggi $52 \%$ (tamat SMU), pernah mengikuti pendidikan non formal (97\%) dimana 31\% pernah mengikuti 4 - 5 kali. Kondisi ekonomi responden umumnya tinggi terlihat dari $32 \%$ berependapatan lebih dari Rp. 8.000.000/ tahun serta $44 \%$ mempunyai tanggungan 2 anak. Pengalaman sebagai nelayan $76 \%$ lebih dari 10 tahun, selama menjadi nelayan 94\% responden pernah membeli alat ke luar daerah dan $84 \%$ pernah mencari informasi ke luar daerah (Tabel 2).

\section{Partisipasi}

Tingkat partisipasi responden dalam pengelolaan KKL Kabupaten Ciamis sebesar (32\%) sering mengikuti (baik) dan $15 \%$ selalu mengikuti (Gambar 7). Dari hasil wawancara dengan 100 responden dapat diketahui $25,7 \%$ sering mengikuti kegiatan perencanaan, $25,8 \%$ sering mengikuti kegiatan penyuluhan/ pembinaan dan $16 \%$ sering ikut dalam kegiatan pemecahan masalah pengelolaan KKL Kabupaten Ciamis (Tabel 3).

Karakteristik responden yang berhubungan dengan partisipasi dalam perencanaan KKL adalah umur, pendapatan dan membeli alat/ perlengkapan ke luar daerah. Sedangkan pendidikan formal, pendapatan dan pengalaman responden berhubungan terhadap partisipasi dalam penyuluhan dan pembinaan. Tingkat partisipasi responden dalam pemecahan kendala berhubungan dengan umur, pendidikan non formal, pendapatan, pengalaman dan kegiatan mencari informasi ke luar daerah (nilai probabilitas < 0,05). Keaktifan responden berpartisipasi dalam pengelolaan KKL Kabupaten Ciamis berhubungan dengan tingkat pendapatannya (Tabel 4).

\section{Pembahasan}

Sebagian besar responden (88\%) masuk dalam kategori usia produktif dimana rata-rata usia nelayan Kabupaten Ciamis 43 tahun. Keadaan ini berkaitan erat dengan komposisi penduduk usia produktif di wilayah penelitian sebanyak $68,2 \%$ dari total penduduk. Jika jumlah usia produktif tinggi namun lapangan kerja yang terbatas maka tekanan terhadap lingkungan hidup berpotensi tinggi. Keadaan penduduk ini dapat mengancam lingkungan hidup, termasuk KKL. Bentuk tekanan lingkungan ini misalnya kegiatan pemanfaatan secara destruktif terhadap sumber daya alam yang tersedia di terumbu karang dan hutan mangrove. Di sisi lain, jika sumber daya alam ini dikelola dengan baik dan masyarakat memahami manfaat dari kelestarian lingkungan hidup maka KKL memiliki potensi menyediakan lapangan pekerjaan, baik secara langsung maupun tidak langsung.

Pada setiap kecamatan di Kabupaten Ciamis telah tersedia sarana pendidikan untuk semua jenis tingkat, kecuali perguruan tinggi. Pendidikan rata-rata nelayan Ciamis tamat SMP. 
Kondisi ini merupakan potensi yang dapat dikelola dengan baik agar tercipta sumberdaya manusia yang berkualitas, berwawasan luas dan jangka panjang. Kualitas sumberdaya manusia yang rendah (dengan pengetahuan dan keterampilan yang terbatas serta sikap dan moral yang negatif) akan berdampak buruk terhadap pembangunan, termasuk menghambat proses pemberdayaan dan pemahaman mereka terhadap fungsi, manfaat dan pemeliharaan sumberdaya laut dan pesisir.

Tingkat pendapatan nelayan berkaitan erat dengan jumlah sumber mata pencaharian. Di Ciamis, Rumah Tangga Perikanan (RTP) yang berpendapatan tinggi didominasi oleh pemilik perahu dan nelayan yang memiliki anggota keluarga yang bekerja (misalnya istri sebagai bakul ikan, pengolah ikan). RTP yang berpendapatan rendah didominasi oleh nelayan penuh (disebut "janggol") dan tidak memiliki anggota keluarga yang bekerja.

Tingkat keterbukaan responden termasuk tinggi karena interaksi mereka dengan dunia luar. Sebagian besar responden kadang-kadang mencari informasi dan membeli alat/ perlengkapan di luar Ciamis. Rogers (1969) mengatakan bahwa keterbukaan dapat meningkatkan kemampuan berempati dan daya empati ini akan meningkatkan sifat inovatif, komunikasi dan aspirasi. Tingkat keterbukaan responden yang tergolong tinggi ini tentunya dapat mempengaruhi tingkat persepsi dan partisipasi dalam pengelolaan KKL Kabupaten Ciamis.

Proporsi responden yang mengikuti kegiatan perencanaan, kegiatan penyuluhan/pembinaan dan pemecahan masalah pengelolaan KKL berturut-turut masing-masing adalah $25,7 \%, 25,8 \%$ dan $16 \%$. Melihat jenis kegiatan-kegiatan tersebut, jenis partisiapsi masyarakat Cimais baru sebatas pada partisipasi inisiasi. Jenis partisipasi ini terjadi pada kegiatan yang digagas pemimpin, baik pemimpin formal maupun informal, ataupun dari anggota masyarakat tentang suatu program, proyek atau kegiatan yang dirancang untuk memenuhi kebutuhan masyarakat (Hoofsteede, 1971).

Dari segi jumlah kehadirannya, jenis partisipasi yang dilakukan masyarakat Ciamis adalah bentuk partisipasi representatif atau perwakilan yang berdasarkan pada pemberian kepercayaan atau mandat (Soelaiman, 1991). Peserta yang terlibat dalam kegiatan tersebut adalah tokoh atau pengurus dari kelompok masyarakat (seperti kelompok nelayan). Kecukupan partisipasi ini mengandalkan pada asumsi bahwa para wakil tersebut sudah membawa aspirasi kelompok yang diwakilinya. Oleh karena itu, tidak semua anggota masyarakat secara fisik berpartisipasi langsung dalam kegiatankegiatan pengelolaan.

Secara umum hasil penelitian menunjukan karakteristik responden yaitu umur, pendidikan formal dan non formal, pendapatan, pengalaman, membeli alat/perlengkapan dan mencari informasi keluar daerah menunjukan berhubungan dengan tingkat persepsi dan partisiapsi mereka. Hubungan yang terjadi menyatakan bahwa persepsi dan partisipasi individu dipengaruhi oleh faktor pribadi seperti tingkat pendidikan, umur, kekosmopolitan, sikap dan keterampilan seseorang sangat erat kaitannya dengan tingkat pendidikan, karena pendidikan pada dasarnya berupaya meningkatkan pengetahuan, sikap, dan keterampilan seseorang (Madrie, 1986).

Hubungan tersebut terdapat pada indiktor-indikator persepsi dan partisipasi yang berbeda. Kejadian ini disebabkan oleh perbedaan daya rangsangan yang dimiliki secara individual bersifat pribadi dan unik (Weaver, 1978 dalam Susiatik, 1998). Perbedaan daya rangsangan 
dimungkinkan karena sosialisasi dan kegiatan penyuluhan/pembinaan dari pemerintah masih terbatas yang menyebabkan informasi yang diterima oleh nelayan tentang pengelolaan KKLD tidak merata. Kecendrungan terbatasnya informasi yang diterima responden terjadi karena selama ini kegiatan tersebut belum secara menyeluruh dapat dilakukan secara terpadu oleh berbagai intansi atau dinas terkait.

\section{KESIMPULAN DAN SARAN}

\section{Kesimpulan}

1. Nelayan Ciamis umumnya tergolong kategori usia produktif (umur rata-rata 43 tahun), pendidikan rata-rata tamat SMP dan pernah mengikuti pendidikan non formal, pendapatan rata-rata $\mathrm{Rp}$. 6.130.000/tahun dan memiliki pengalaman selama 15 tahun.

2. Partisipasi nelayan masih kurang karena pemerintah kurang berperan dalam memberikan ruang/peluang bagi masyarkat nelayan untuk berpartisipasi (sistem perwakilan).

3. Keaktifan responden berpartisipasi dalam pengelolaan KKL Kabupaten Ciamis berhubungan dengan tingkat pendapatannya.

\section{Saran}

1. Partisipasi masyarakat dalam pengelolaan KKLD Ciamis perlu ditingkatkan dari sekedar sebagai penerima informasi menjadi pengambil keputusan bersama agar strategi pengelolaan yang juga dimiliki oleh masyarakat yang pada intinya diharapkan menjadi pelaku nyata pendukung pengelolaan KKLD yang efektif.

2. Keberhasilan peningkatan partisipasi masyarakat lokal ini tidak akan lepas dari kemampuannya yang didukung oleh pengetahuan, keterampilan dan sikap yang dapat dibangun melalui program pendidikan, latihan dan penyuluhan untuk topik-topik yang relevan dengan pengelolaan KKLD. 
Tabel 2. Distribusi Frekuensi Karakteristik Responden

\begin{tabular}{|c|c|c|c|}
\hline Karakteristik & Frekuensi & Persentase & Persentase Kumulatif \\
\hline \multicolumn{4}{|c|}{ Umur } \\
\hline$<25$ tahun & 1 & 1.0 & 1.0 \\
\hline $25-34$ tahun & 14 & 14.0 & 15.0 \\
\hline $35-44$ tahun & 44 & 44.0 & 59.0 \\
\hline 45 - 54 tahun & 29 & 29.0 & 88.0 \\
\hline$>55$ tahun & 12 & 12.0 & 100.0 \\
\hline \multicolumn{4}{|c|}{ Pendidikan Formal } \\
\hline Tidak Sekolah & 3 & 3.0 & 3.0 \\
\hline Tamat SD & 18 & 18.0 & 21.0 \\
\hline Tamat SMP & 27 & 27.0 & 48.0 \\
\hline Tamat SMA & 52 & 52.0 & 100.0 \\
\hline \multicolumn{4}{|c|}{ Pendidikan Non Formal } \\
\hline$>5$ kali & 28 & 28.0 & 28.0 \\
\hline $4-5$ kali & 31 & 31.0 & 59.0 \\
\hline $2-3$ kali & 28 & 28.0 & 87.0 \\
\hline 1 kali & 10 & 10.0 & 97.0 \\
\hline belum pernah & 3 & 3.0 & 100.0 \\
\hline \multicolumn{4}{|c|}{ Pendapatan/ tahun } \\
\hline$<2$ juta & 8 & 8.0 & 8.0 \\
\hline $2-4$ juta & 11 & 11.0 & 19.0 \\
\hline $4-6$ juta & 18 & 18.0 & 37.0 \\
\hline $6-8$ juta & 31 & 31.0 & 68.0 \\
\hline$>8$ juta & 32 & 32.0 & 100.0 \\
\hline \multicolumn{4}{|c|}{ Jumlah Tanggungan Anak } \\
\hline Tidak ada & 11 & 11.0 & 11.0 \\
\hline 1 orang & 22 & 22.0 & 33.0 \\
\hline 2 orang & 44 & 44.0 & 77.0 \\
\hline 3 orang & 11 & 11.0 & 88.0 \\
\hline 4 orang & 12 & 12.0 & 100.0 \\
\hline \multicolumn{4}{|c|}{ Pengalaman } \\
\hline$<5$ tahun & 2 & 2.0 & 2.0 \\
\hline $5-10$ tahun & 22 & 22.0 & 24.0 \\
\hline $11-15$ tahun & 23 & 23.0 & 47.0 \\
\hline $16-20$ tahun & 26 & 26.0 & 73.0 \\
\hline$>20$ tahun & 27 & 27.0 & 100.0 \\
\hline \multicolumn{4}{|c|}{ Membeli Alat/ Perlengkapan ke Luar Daerah } \\
\hline Tidak Pernah & 6 & 6.0 & 6.0 \\
\hline Jarang & 27 & 27.0 & 33.0 \\
\hline Kadang-kadang & 48 & 48.0 & 81.0 \\
\hline Sering & 10 & 10.0 & 91.0 \\
\hline Selalu & 9 & 9.0 & 100.0 \\
\hline \multicolumn{4}{|c|}{ Mencari Informasi ke Luar Daerah } \\
\hline Tidak Pernah & 16 & 16.0 & 16.0 \\
\hline Jarang & 30 & 30.0 & 46.0 \\
\hline Kadang-kadang & 44 & 44.0 & 90.0 \\
\hline Sering & 6 & 6.0 & 96.0 \\
\hline Selalu & 4 & 4.0 & 100.0 \\
\hline
\end{tabular}


Tabel 3. Partisipasi Responden dalam Perencanaan, Penyuluhan/ Pembinaan dan Pemecahan Kendala Pengelolaan KKL Kabupaten Ciamis.

\begin{tabular}{|c|c|c|c|c|c|c|c|}
\hline \multirow{2}{*}{ Partisifasi } & \multirow{2}{*}{$\begin{array}{l}\text { No } \\
\text { Pertanyaan }\end{array}$} & \multicolumn{5}{|c|}{ Jawaban Responden } & \multirow{2}{*}{ Jumlah } \\
\hline & & TP & $\mathbf{J}$ & KK & $\mathbf{S}$ & SL & \\
\hline \multirow{3}{*}{ Perencanaan } & 1 & 1 & 5 & 38 & 27 & 29 & 100 \\
\hline & 2 & 5 & 4 & 38 & 28 & 25 & 100 \\
\hline & 3 & 16 & 3 & 46 & 22 & 13 & 100 \\
\hline \multicolumn{2}{|l|}{ Jumlah } & 22 & 12 & 122 & 77 & 67 & 300 \\
\hline \multicolumn{2}{|l|}{ Persentase (\%) } & 7,3 & 4 & 40,7 & 25,7 & 22,3 & 100 \\
\hline \multirow{5}{*}{$\begin{array}{l}\text { Penyuluhan dan } \\
\text { Pembinaan }\end{array}$} & 4 & 4 & 11 & 36 & 31 & 18 & 100 \\
\hline & 5 & 16 & 8 & 38 & 23 & 15 & 100 \\
\hline & 6 & 16 & 10 & 41 & 23 & 10 & 100 \\
\hline & 7 & 5 & 10 & 40 & 33 & 12 & 100 \\
\hline & 8 & 13 & 11 & 49 & 19 & 8 & 100 \\
\hline \multicolumn{2}{|l|}{ Jumlah } & 54 & 50 & 204 & 129 & 63 & 500 \\
\hline \multicolumn{2}{|l|}{ Persentase (\%) } & 10,8 & 10 & 40,8 & 25,8 & 12,6 & 100 \\
\hline \multirow{2}{*}{$\begin{array}{l}\text { Pemecahan } \\
\text { kendala }\end{array}$} & 9 & 13 & 22 & 37 & 20 & 8 & 100 \\
\hline & 10 & 15 & 11 & 54 & 12 & 8 & 100 \\
\hline \multicolumn{2}{|l|}{ Jumlah } & 28 & 23 & 91 & 32 & 16 & 200 \\
\hline \multicolumn{2}{|l|}{ Persentase (\%) } & 14 & 11,5 & 45,5 & 16 & 8 & 100 \\
\hline
\end{tabular}

Ket: TP: Tidak pernah, J: Jarang, KK: Kadang-kadang, S: Sering, SL: Selalu

Tabel 4. Rekapitulasi Hubungan Karakteristik dengan Partisipasi Responden

\begin{tabular}{|c|c|c|c|c|}
\hline Karakteristik & Partisipasi & Chi-Square & df & Probabilitas \\
\hline \multirow{4}{*}{ Umur } & Perencanaan & 36.252 & 16 & $0,003 *$ \\
\hline & Penyuluhan/Pembinaan & 23.212 & 16 & 0,108 \\
\hline & Pemecahan Kendala & 30.191 & 16 & $0,017^{*}$ \\
\hline & Pengelolaan KKLD & 114.156 & 16 & $0, .000 *$ \\
\hline \multirow{4}{*}{$\begin{array}{l}\text { Pendidikan } \\
\text { formal }\end{array}$} & Perencanaan & 7.801 & 12 & 0,800 \\
\hline & Penyuluhan/Pembinaan & 24.565 & 12 & $0,017^{*}$ \\
\hline & Pemecahan Kendala & 11.067 & 12 & 0,523 \\
\hline & Pengelolaan KKLD & 10.429 & 12 & 0,578 \\
\hline \multirow{4}{*}{$\begin{array}{l}\text { Pendidikan non } \\
\text { formal }\end{array}$} & Perencanaan & 19.413 & 16 & 0,248 \\
\hline & Penyuluhan/Pembinaan & 19.940 & 16 & 0,223 \\
\hline & Pemecahan Kendala & 34.395 & 16 & $0,005^{*}$ \\
\hline & Pengelolaan KKLD & 23.254 & 16 & 0,107 \\
\hline \multirow{4}{*}{ Pendapatan } & Perencanaan & 40.232 & 16 & $0,001^{*}$ \\
\hline & Penyuluhan/Pembinaan & 39.626 & 16 & $0,001^{*}$ \\
\hline & Pemecahan Kendala & 29.673 & 16 & $0,020^{*}$ \\
\hline & Pengelolaan KKLD & 24.870 & 16 & 0,072 \\
\hline \multirow{4}{*}{$\begin{array}{l}\text { Jumlah } \\
\text { tanggungan } \\
\text { anak }\end{array}$} & Perencanaan & 19.808 & 16 & 0,229 \\
\hline & Penyuluhan/Pembinaan & 13.353 & 16 & 0,647 \\
\hline & Pemecahan Kendala & 10.109 & 16 & 0,861 \\
\hline & Pengelolaan KKLD & 21.054 & 16 & 0,176 \\
\hline \multirow{4}{*}{ Pengalaman } & Perencanaan & 22.602 & 16 & 0,125 \\
\hline & Penyuluhan/Pembinaan & 39.382 & 16 & $0,001^{*}$ \\
\hline & Pemecahan Kendala & 33.259 & 16 & $0,007^{*}$ \\
\hline & Pengelolaan KKLD & 62.715 & 16 & $0,000^{*}$ \\
\hline \multirow{4}{*}{$\begin{array}{l}\text { Beli alat/ } \\
\text { perlengkapan } \\
\text { ke luar daerah }\end{array}$} & Perencanaan & 42.259 & 16 & $0,000^{*}$ \\
\hline & Penyuluhan/Pembinaan & 34.807 & 16 & $0,004^{*}$ \\
\hline & Pemecahan Kendala & 16.498 & 16 & 0,419 \\
\hline & Pengelolaan KKLD & 21.666 & 16 & 0,154 \\
\hline \multirow{4}{*}{$\begin{array}{l}\text { Mencari } \\
\text { informasi ke } \\
\text { luar daerah }\end{array}$} & Perencanaan & 20.847 & 16 & 0,184 \\
\hline & Penyuluhan/Pembinaan & 18.090 & 16 & 0,319 \\
\hline & Pemecahan Kendala & 35.540 & 16 & $0,003 *$ \\
\hline & Pengelolaan KKLD & 15.585 & 16 & 0,482 \\
\hline
\end{tabular}

$*$ Berhubungan (probabilitas $<0,05$ ) 


\section{DAFTAR PUSTAKA}

Arikunto, S. 2002. Prosedur Suatu Penelitian: Pendekatan Praktek. Edisi Revisi. Kelima. Rineka Cipta. Jakarta.

BPS Ciamis. 2011. Kabupaten Ciamis dalam Angka (Ciamis in Figurs) 2011. Badan Pusat Statistik. Ciamis.

Hoofsteede. 1971. Proses Pengambilan Keputusan di Empat Desa Jawa Barat. Gajah Mada University Press. Yogyakarta.

Koentjaraningrat. 1997. Metode-Metode Penelitian Masyarakat. PT. Gramedia Pustaka Utama. Jakarta.

Madrie. 1986. Beberapa Faktor Penentu Anggota Masyarakat dalam Pembangunan (Kasus : Desa-desa di Kecamatan Palas-Lampung. Tesis. Bogor. Pascasarjana IPB

Pomeroy, R. dan F. Berkes. 1997. Two to Tango : the Role of Government in Fisheries Co-Management. Marine Policy.

Rogers, E.M., dan Shoemaker, F. F. 1969. Communication of
Innovation: Across Cultural Approach. The Free Fress. New York

Soelaiman, H. 1991. Partisipasi Masyarakat. STKS. Bandung.

Subiyakto, H. 1994. Statistika 2. Gunadarma. Jakarta.

Sugiyono. 2006. Metode Penelitian Bisnis, cetakan kesembilan. C. V. Alvabeta. Bandung.

Susiatik, T. 1998. Persepsi dan Partisipasi Masyarakat Terhadap Kegiatan Pembangunan Masyarakat Desa Hutan Terpadu (PMDHT) di Desa Mojorebo Kecamatan Wirosari Kabupaten Dati II Grobogan Jawa Tengah. Tesis. Bogor: IPB.

Umar, H. 2004. Riset Sumberdaya Manusia. Gramedia Pustaka Utama. Jakarta.

White, A., L.Z. Hale, Y. Renard and L. Cortesi. 1994. Collaborative and Community Management of Coral Reefs: Lessons from Experience. Kumarian Press, Connecticut, USA. 